\title{
Somatic Embryogenesis in Iberian Grapevine (Vitis vinifera) Cultivars Using Carpels as Initial Explants: Protocol Establishment and Histological Evaluation
}

\author{
Hélia Guerra Cardoso ${ }^{1}$, Maria Catarina Campos ${ }^{1}$, Maria Salomé Pais $^{2}$ and Augusto Peixe ${ }^{3}$ \\ 1. ICAAM-Mediterranean Institute of Agronomical and Environmental Sciences, Institute for Advanced Research and Formation, \\ Évora University, Pólo da Mitra, Ap. 94, 7006-554 Évora, Portugal \\ 2. Plant Molecular Biology and Biotechnology Laboratory, Unit of Molecular Biology and Plant Biotechnology (BioFIG), FCUL \\ Campus, C2.2.12, Campo Grande 1749-016, Lisboa, Portugal \\ 3. Plant Science Department, ICAAM, Science and Technology School, Évora University, Pólo da Mitra, Ap. 94, 7006-554 Évora, \\ Portugal
}

\begin{abstract}
Trincadeira and Aragonez are two important grapevine cultivars in the Iberian Peninsula, used for high quality red wines production. Both cultivars are strongly affected by fungal diseases, with consequent high loses on plant productivity and fruit quality. A successful protocol for plant regeneration via somatic embryogenesis (SE) was established for both cultivars allowing further plant improvement based on gene transfer technology. Several factors were evaluated during the three different phases which characterize an SE plant regeneration protocol. The culture room temperature during the induction phase, a parameter usually accepted as standard by most researchers, proved in these trials to significantly affect the embryo induction rates. Concerning embryo conversion, it was specially affected by the embryo developmental stage, by the intensity and duration of the chilling treatment and by the supplementation of conversion culture medium with activated charcoal. The responses obtained, both for induction and conversion, proved to be highly genotype dependent. Calli structure, as well as embryo integrity, was histologically observed, allowing to characterize embryonic and non-embryonic masses and to identify abnormalities on embryo development.
\end{abstract}

Key words: Aragonez, Trincadeira, grapevine, megasporogenesis, somatic embryogenesis.

\author{
Abbreviations \\ BAP: 6-benzylaminopurine; \\ 2,4-D: 2,4-dichlorophenoxyacetic acid; \\ NAA: 1-naphtalene acetic acid; \\ SE: somatic embryogenesis; \\ IM: induction medium; \\ DM: differentiation medium; \\ CM: conversion medium.
}

\section{Introduction}

The grapevine (Vitis spp.) is one of the most important fruit crops worldwide, with a total vineyard area of 7.5 Mha [1]. Spain and Portugal, two

Corresponding authors: Hélia Guerra Cardoso (researcher) and Augusto Peixe (professor), research fields: molecular biology and plant biotechnology. important wine producers, contribute with $19 \%$ of the world's vineyards. The Vitis vinifera L. cultivars Trincadeira and Aragonez, the latter also named Tinta Roriz in the north of Portugal and Tempranillo in Spain, are important for high-quality red wines production in the Iberian Peninsula.

Like most $V$. vinifera, those cultivars present a high sensitivity to powdery and downy mildew diseases, a problem that can lead into a dramatic decrease of the winegrower economic profit. Improving the disease resistance of these cultivars would be welcome, especially if their important agronomic traits were not altered [2].

The use of genetic engineering techniques would have a real impact on grapevine breeding, due to the 
ability of directly transfer a single trait into the genome, while leaving unchanged the distinctive characteristics of the cultivar.

As stated by Gray et al. [3], several techniques including cell culture systems to allow efficient plant regeneration, advanced gene insertion and genomic analyses, experimented huge developments recently. These techniques are being used for high-throughput expression analysis of a wide range of grapevine-derived promoters and disease-related genes, being envisioned that future research efforts will be extended to the study of promoters and genes functioning to enhance other important traits, such as fruit quality and plant vigor [3]. This knowledge on differential gene expression dealing with important agronomical traits, may present a new opportunity not only for transgenic, but also for precision ("cisgenic") and transient plant transformation approaches.

Efficient protocols for genetic transformation of both cultivars under evaluation were already established [4, 5], but, the development of an efficient plant regeneration system from cultured cells and tissues, a prerequisite to successfully apply those genetic transformation protocols, was not accomplished yet.

SE in grapevine was first achieved in 1970s and represents nowadays one of the most suitable tools for genetic improvement in the Vitis genus. This is related with the high proliferation rates and regeneration skills that can be attained [6-11], associated with the frequent single cell origin of the somatic embryos, which avoids the problem of chimer regeneration [12]. However, the efficiency of this methodology is still dependent on a complex interaction among different factors like the genotype of donor plant, the explant type and developmental stage, or the chemical media composition [13-20].

In $V$. vinifera the most successful and reliable protocols for SE induction and subsequent embryo conversion, were obtained using reproductive organs (anthers and ovaries) as initial explants [5, 7, 15, 19,
21-36] and the microspore and the ovule developmental stages were stated as major factors affecting embryogenesis efficiency [17, 19, 33, 37].

Difficulties in producing mature and normally developed somatic embryos, able to evolve into normal plants, are an additional limitation for the SE grapevine protocols $[28,29,38,39]$. The embryo developmental stage, its dormancy level and the composition of the culture media, are just a few factors limiting the success of this procedure $[31,40]$. Nevertheless, also here, the genotype dependence is referred as the major factor affecting the ability of embryos conversion [7].

The number of Vitis species and cultivars to whom SE protocols were developed is continuously increasing $[16,23,35]$ but the technique is far away from becoming routinely and widely used, which explains the need to develop improved methodologies for each valuable genotype. In fact, most reports on grapevine SE are focused on few elite cultivars.

Portugal and Spain hold up one of the most important grapevine genetic pools in the world, with more than 350 distinctive cultivars already classified, but, few reports on successful SE for those cultivars are known.

In this study, an efficient protocol was established for the regeneration of two Iberian $V$. vinifera cultivars through SE. The effect of the inflorescences chilling pre-treatment and incubation temperature on SE efficiency was evaluated. The efficiency of growth regulators (2,4-D or NAA in combination with BAP) on embryos differentiation was also tested. Embryo developmental stage and distinct physical and chemical conditions were analyzed to develop the most appropriate protocol for embryos conversion.

\section{Materials and Methods}

\subsection{Plant Material}

Based on correlations previously established between the flower bud/anther dimensions, the 
evolution of macro and microsporogenesis and its effect on the rates of SE [17], inflorescences from the Aragonez and Trincadeira cultivars, with flower buds enclosing anthers with a mean size of $0.5 \mathrm{~mm}$, were collected in vineyard-growing plants from the PLANSEL grapevine nursery, at Quinta do Canal, Montemor-o-Novo, Portugal.

\subsection{Culture Conditions}

\subsubsection{Embryogenesis Induction}

Chilling pre-treatment of the inflorescences and incubation temperature of the in vitro cultures were the factors under evaluation. To analyze the effect of chilling pre-treatment, the inflorescences involved in wet paper were placed into plastic bags and kept at $4{ }^{\circ} \mathrm{C}$ during 0,7 and $14 \mathrm{~d}$, under dark conditions, before in vitro inoculation. After each period the inflorescences were surface sterilized, the carpels aseptically excised and inoculated in IM [17] supplemented with $5 \mu \mathrm{M}$ of 2,4-D and $1 \mu \mathrm{M}$ of BAP. The cultures were incubated in the dark for $30 \mathrm{~d}$ at 25 , 28 , or $35{ }^{\circ} \mathrm{C}$. Twenty-five carpels were placed per Petri dish $(6 \mathrm{~cm} \varnothing)$ (see Fig. 1 for the complete experimental design).

\subsubsection{Embryogenesis Differentiation}

Carpels presenting calli development were transferred into fresh IM, supplemented with $1 \mathrm{~g} / \mathrm{L}$ of hydrolysed casein and lacking L-phenilalanine. This medium, named DM, was added with 2,4-D or NAA and BAP, in the following proportions: 0:0, 1:0 or 5:1. Cultures were kept at $25^{\circ} \mathrm{C}$, with a $16 \mathrm{~h}$ photoperiod and $34 \mu \mathrm{mol} / \mathrm{m}^{2} / \mathrm{s}$ of light intensity, provided by Philips day-light fluorescent lamps.

\subsubsection{Embryo Conversion}

Embryos belonging to three predefined groups (I. globular and heart-shape stages; II. torpedo and early cotyledonary stages; III. late cotyledonary stage), were individualized and horizontally inoculated on Petri dishes $(6 \mathrm{~cm} \varnothing)$ containing $\mathrm{CM}$, which consists in IM formulation devoid of growth regulators (for embryo stage identification see Fig. 2). The cultures were kept under the same growth condition as described for embryogenesis differentiation. Distinct physical and chemical conditions were also tested after selection of the stage II (torpedo and early cotyledonary stages) as the most appropriate for embryo conversion. Embryos at that stage were horizontally inoculated on Petri dishes $(6 \mathrm{~cm} \varnothing)$ containing $\mathrm{CM}$. The following factors were tested: addition of activated charcoal $(2 \mathrm{mg} / \mathrm{L})$; addition of BAP $(0.4 \mu \mathrm{M})$ or $\mathrm{GA}_{3}(1 \mu \mathrm{M})$; cold treatment, studied by keeping the embryos at $4{ }^{\circ} \mathrm{C}$ for 5,15 or $25 \mathrm{~d}$. All cultures were kept on the same conditions as previously described. Trials consisted in four repetitions per treatment, each repetition corresponding to one Petri dish with 25 embryos. All developed embryos (1 cm length) arising from the previously described treatments, were vertically inoculated in test-tubes (one embryo per tube) containing $\mathrm{CM}$ and maintained under the growth conditions previously described.

\subsection{Histology}

To evaluate the cellular differences among the several calli types, samples of callogenic tissue were collected, placed on a microscope blade and observed, using an Olympus CX40 light microscope, after being smashed in a few drops of acetic orcein $(1 \mathrm{~g} / \mathrm{L})$.

To analyze the origin of the embryonic calli and/or adventitious embryos, explants were collected weekly at $0,7,14,21$ and $28 \mathrm{~d}$ after in vitro inoculation and prepared for histological observation according to the procedure previously described by Cardoso et al. [17].

\subsection{Data Analysis}

The effect of chilling pre-treatment and incubation temperature on embryogenesis induction was evaluated by the number of explants exhibiting embyogenic calli $30 \mathrm{~d}$ after inoculation in IM.

SE efficiency was evaluated by the number of somatic embryos formed and was recorded four weeks after embryogenic calli inoculation on DM. All data 


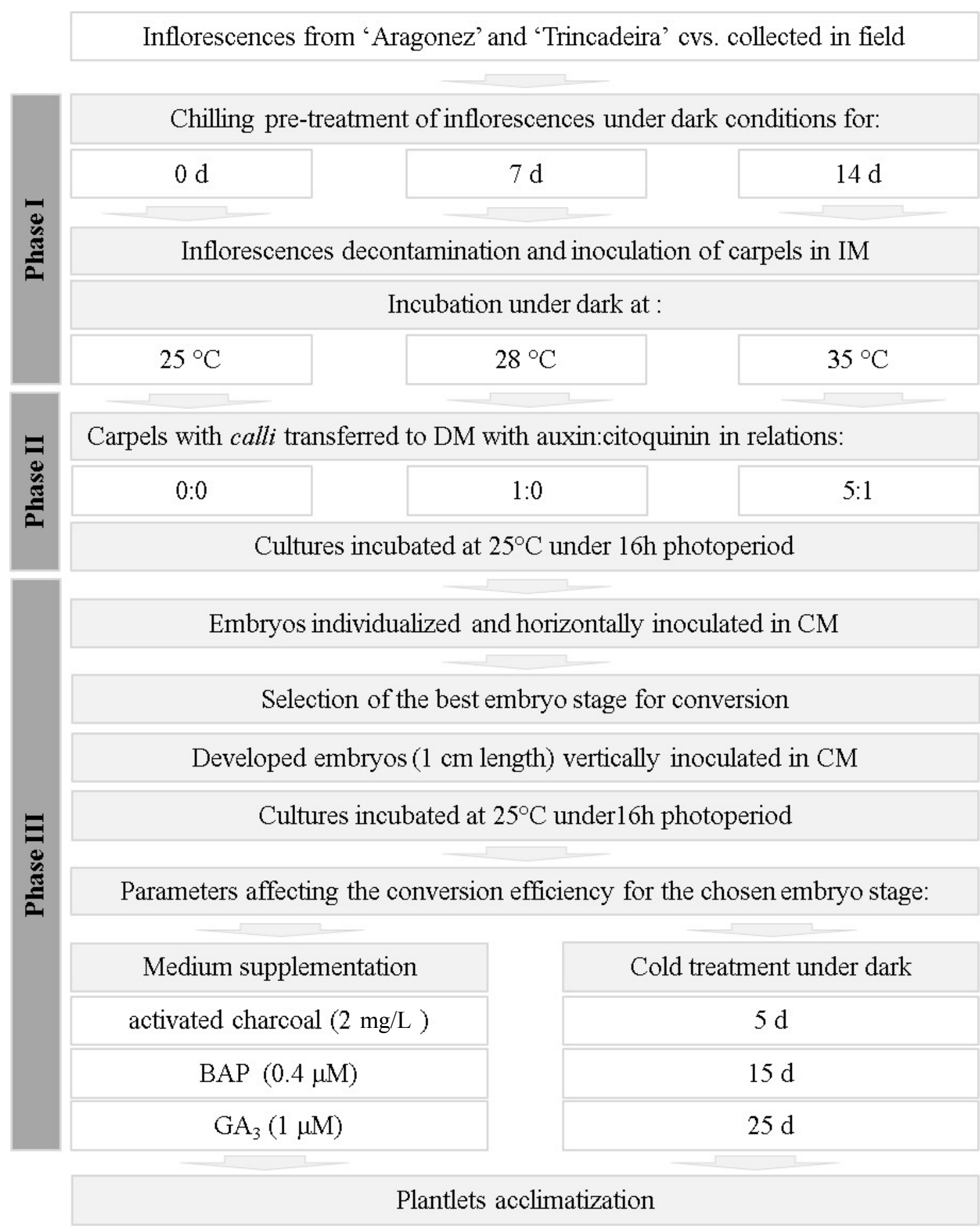

Fig. 1 Scheme of the experimental design followed in the present work.

Phase I: induction phase; Phase II: differentiation phase; Phase III: conversion phase. 

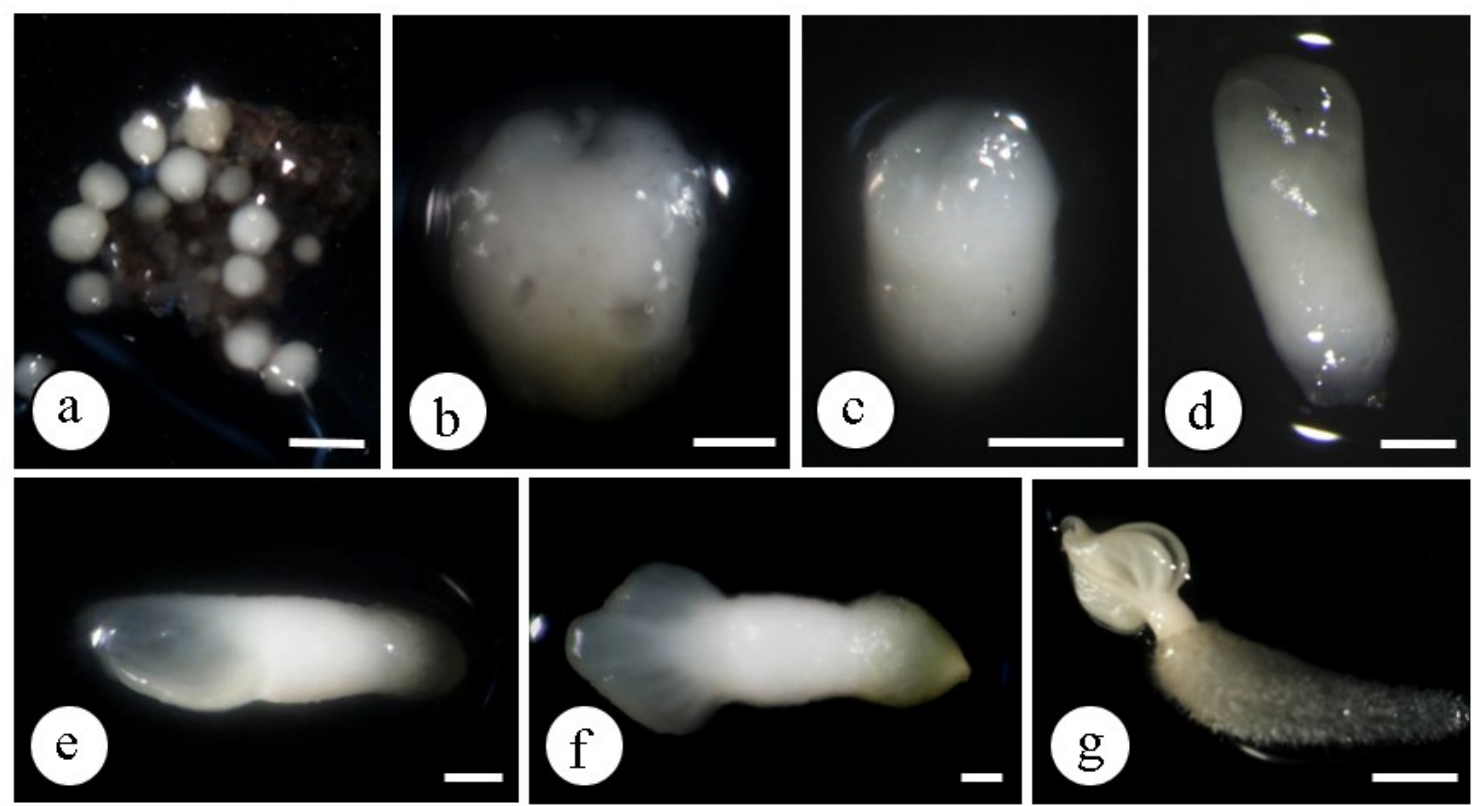

Fig. 2 Embryos developmental stages: globular stage (a); cordiforme stage (b); torpedo stage (c and d); early cotyledonary stage (e); cotyledonary stage (f); late cotyledonary stage (g).

Bars in a, d, e, f and g: $500 \mu \mathrm{m}$; bars in b and c: $100 \mu \mathrm{m}$.

related with callogenesis and embryogenesis were analyzed on base of the final number of in vitro carpels and not on base of the number of inoculated explants, because some contaminations reduced the initial number of inoculated carpels.

Embryo conversion efficiency was determined by the presence of embryos showing tap root and at least one axillary bud, in relation with the total of inoculated embryos four weeks after embryos transfer to test-tubes containing CM.

Numerical data were analyzed by one-way analysis of variance (ANOVA) followed by Student-Newman-Keuls multiple means test comparison, at a significance level of $p \leq 0.05$ using the software SPSS version 12.0 for Windows (SPSS Inc. 2003).

\section{Results and Discussion}

\subsection{Embryogenesis Induction}

Chilling pre-treatment of the inflorescences at $4{ }^{\circ} \mathrm{C}$ was the first factor tested and revealed to have a negative effect on the SE induction rates for the Aragonez cultivar. Indeed, the rate of carpel calli presenting somatic embryos, was significantly higher on those arising from inflorescences not submitted to cold treatment (10.7\%) (Table 1). For the Trincadeira cultivar, which always presented lower SE rates than the obtained for Aragonez, no significant differences were detected between the chilling pre-treatments and the control (Table 1).

A positive effect of cold pre-treatments of inflorescences was previously associated with an increase of the SE efficiency in some grapevine cultivars, both, for anther and ovary cultures [31, 34, 36]. When the anther culture is used, this positive effect is usually associated with the synchronization of microsporogenesis evolution stages, which seems to increase the number of microspores able to evolve into the sporophytic pathway [41]. In carpels culture, the effect of a chilling pre-treatment of inflorescences remains unclear, and in the present study, no positive results were observed. A negative effect of a $4{ }^{\circ} \mathrm{C}$ pre-treatment in cv. Aragonez, was already reported by Cutanda et al. [21], while using anthers of this cultivar as initial explants, and corroborate the results now presented for carpel culture. 
Table 1 Effect of the chilling pre-treatment on embryogenesis induction.

\begin{tabular}{llllc}
\hline \multirow{2}{*}{$4{ }^{\circ} \mathrm{C}$ treatment $(\mathrm{d})$} & \multicolumn{2}{c}{ Aragonez } & \multicolumn{2}{c}{ Trincadeira } \\
\cline { 2 - 5 } & $\mathrm{N}(\mathrm{n})$ & Embryogenesis $(\%)$ & $\mathrm{N}(\mathrm{n})$ & Embryogenesis $(\%)$ \\
\hline 0 & $525(21)$ & $10.7 \pm 1.5 \mathrm{a}$ & $424(17)$ & $5.0 \pm 1.5 \mathrm{a}$ \\
7 & $576(24)$ & $5.9 \pm 1.4 \mathrm{~b}$ & $528(22)$ & $3.0 \pm 1.4 \mathrm{a}$ \\
14 & $592(24)$ & $3.3 \pm 1.4 \mathrm{~b}$ & $340(14)$ & $5.0 \pm 1.4 \mathrm{a}$ \\
\hline
\end{tabular}

$\mathrm{N}$ : corresponds to the number of carpels inoculated in IM after discarded the carpels with contaminations; n: corresponds to the number of Petri dishes.

Different letters in the same column means significant differences $(p \leq 0.05)$ based on the Student-Newman-Keuls test Post-Hoc ANOVA.

Table 2 Effect of the induction temperature on the embryogenesis induction.

\begin{tabular}{lllll}
\hline Incubation temperature $\left({ }^{\circ} \mathrm{C}\right)$ & \multicolumn{2}{c}{ Aragonez } & \multicolumn{2}{c}{ Trincadeira } \\
\cline { 2 - 5 } & $\mathrm{N}(\mathrm{n})$ & Embryogenesis frequency $(\%)$ & $\mathrm{N}(\mathrm{n})$ & Embryogenesis frequency $(\%)$ \\
\hline 25 & $558(23)$ & $3.4 \pm 0.14 \mathrm{~b}$ & $472(19)$ & $2.0 \pm 1.5 \mathrm{a}$ \\
28 & $563(23)$ & $9.6 \pm 0.14 \mathrm{a}$ & $370(16)$ & $5.0 \pm 1.4 \mathrm{a}$ \\
35 & $572(23)$ & $6.4 \pm 0.14 \mathrm{ab}$ & $450(18)$ & $5.0 \pm 1.4 \mathrm{a}$ \\
\hline
\end{tabular}

$\mathrm{N}$ : corresponds to the number of carpels inoculated in IM after discarded the carpels with contaminations; $\mathrm{n}$ : corresponds to the number of Petri dishes.

Different letters in the same column means significant differences $(p \leq 0.05)$ based on the Student-Newman-Keuls test Post-Hoc ANOVA.

Regarding the incubation temperature $(25,28$ and $35^{\circ} \mathrm{C}$ ), it significantly affected the SE induction in calli from Aragonez, with the highest rates being obtained in carpels inoculated at $28{ }^{\circ} \mathrm{C}$ and $35{ }^{\circ} \mathrm{C}(10 \%$ and $6 \%$, respectively) (Table 2). For Trincadeira, where the average SE rates were lower, no significant differences were identified among the three temperatures tested (Table 2). The temperature range used during the SE induction phase, was never reported as a factor able to affect SE efficiency. Temperatures ranging from $21^{\circ} \mathrm{C}$ to $26{ }^{\circ} \mathrm{C}$ are used in most of the published protocols, without any reference to previous optimizations [16, 19, 24, 26, 27, 32, 36, 42].

Concerning the histological study, carried to follow-up carpel evolution in culture, the initial observations confirmed the carpel developmental stage at the inoculation time (day 0), as being the stage I (carpels enclosing ovules as a small conical protuberance developed from the placenta). Seven days after inoculation no changes in carpels appearance were detected (Fig. 3a). After $14 \mathrm{~d}$, cell divisions were observed on the ovule and callus development begun at the ovary receptacle tissues (Fig. 3b). Between $21 \mathrm{~d}$ and $28 \mathrm{~d}$, the ovules continue their growth inside the locus (Figs. 3c and 3d), and adventitious embryos in globular and heart-shape stages were already developed from the pre-formed calli (Fig. 3e). Somatic embryos tend to naturally separate from one other and independently continue their development. At the cellular level, they are comprised by uniform small size cells, characterized by dense cytoplasm with visible starch grains and presenting prominent nuclei and nucleoli (Figs. 3f and 3g).

After $28 \mathrm{~d}$ in the IM, the number of calli showing development of somatic embryos greatly increased and significant changes could be observed in the external appearance of the explants. The carpels lost their green color and increased in size, but preserved its initial structure (Fig. 4a). The developed calli presented a heterogeneous appearance in structure and color, allowing to classify them in four different types: white/pale yellow with nodular appearance, brown and friable, white and compact, white and filamentous (Figs. 4a-4c). 
Somatic Embryogenesis in Iberian Grapevine (Vitis vinifera) Cultivars Using Carpels as Initial Explants: Protocol Establishment and Histological Evaluation
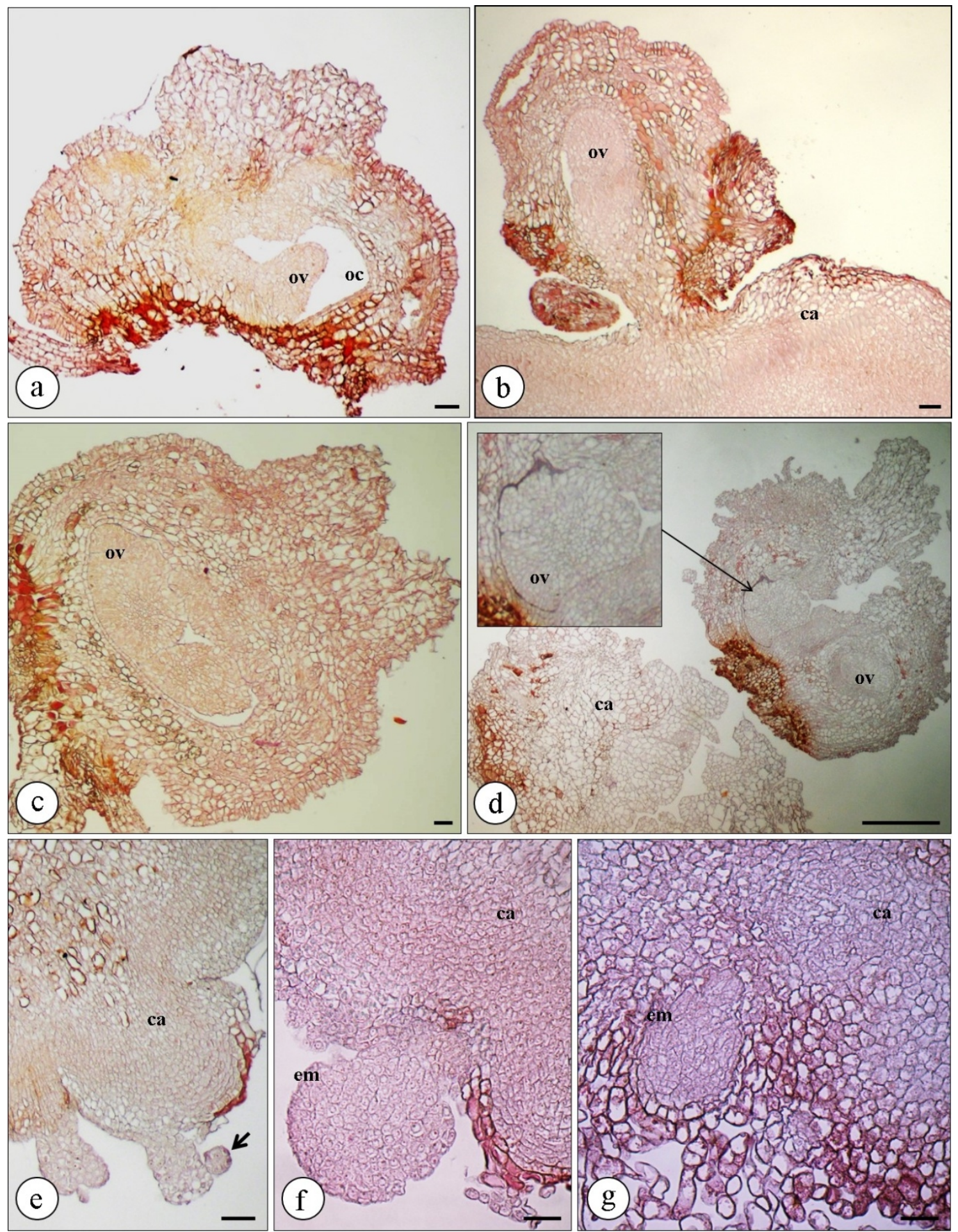

Fig. 3 Histological examination of immature carpel explants of Vitis vinifera cv. Trincadeira during the induction phase of SE. Longitudinal section obtained after $7 \mathrm{~d}$ of in vitro inoculation in IM; the ovule (ov) is visible inside the locus (oc) as a conical protuberance developed from the placenta characteristic of the ovule developmental stage $I$ (a); section at $14 \mathrm{~d}$ showing the development of callus (ca) starting from the ovary receptacle region (b); section at $21 \mathrm{~d}$ showing the increased growth of the ovule (ov) inside the locus (c); section at $28 \mathrm{~d}$ showing the callus developed from the ovary receptacle tissue (d); globular embryos (arrow) developed from embryogenic callus after $21 \mathrm{~d}$ (e); embryos (em) observed from embryogenic callus after $28 \mathrm{~d}$ (f and g). Bar in a, b, c, e, f and g: $100 \mu \mathrm{m}$; bar in d: $1,000 \mu \mathrm{m}$. 
It was observed that callus morphology and embryogenic competence were highly correlated. Only the white/pale yellow granular calli presented cells able to differentiate into embryonic structures. Similar differences in callus morphology have been reported by different authors using several plant tissues as initial explant [42-45]. In all repots it has been made the association of white to pale yellow granular calli appearance with the potentiality for somatic embryo differentiation. Microscopic observation of cells from the different calli types revealed that when compared with other cell types (Figs. 4d-4f), the embryonic cells tend to be smaller, with dense cytoplasm, conspicuous nuclei and thick cell walls (Fig. 4g).

Calli development was observed arising from the ovary receptacle (excision region) and from the nucellar tissues. Nakano and colleagues [32], working with $V$. vinifera L. cv. 'Neo Mat', also reported such pattern for callus development. The reactiveness of the nucellar tissues leading to calli development was already reported for $V$. vinifera $[46,47]$. Nevertheless, the non-reactiveness of those tissues was also found in several cultivars [28, 32], suggesting a genotype dependence on the callogenesis response of nucellar tissues. However, the physiological carpel stages at incubation time, can also be considered as putatively affecting that response [17]. In fact, Nakano et al. [32] worked with carpels in stage $\mathrm{V}$, showing anatropous ovules with both integuments and embryo sac developed, while less developed carpels were used in the present study, with ovules looking as small conical protuberances developing from the placenta tissue (stage I) (see characterization of ovule development in Ref. [17]).

\subsection{Embryo Differentiation}

Two weeks after calli transfer into the DM, and after exposition to a $16 \mathrm{~h}$ photoperiod, the carpels reacquired the green color and white globular somatic embryos became visible at the surface of the embryonic carpel-derived calli (Fig. 5a). The somatic embryos development was asynchronous, being usual the presence of embryos in different developmental stages, evolving from the same embryogenic calli (Figs. 5a and 5b). Most cotyledonary embryos exhibited a well-established root/shoot axes and two well-developed cotyledons (Fig. 5b), but some abnormal embryos were also visible, with multiple deformed or fused cotyledons and lacking root meristem (Fig. 5c).

Abnormal and asynchronous maturation of the somatic embryos have been associated with low embryos conversion rates in different grapevine genotypes [28, 40, 43], which justifies the need of protocol optimization to improve somatic embryos conversion ratios of specific cultivars. Faure [48], previously investigated the problem of embryos conversion in $V$. rupestris, at morphological, histological and histochemical levels. The author reported that embryos unable to convert into plants, present a degenerated or absent shoot apex, which often turned to unorganized cellular proliferation. Same author suggested that the water-saturated atmosphere where somatic embryos arise during in vitro culture, could be unfavorable for its conversion, and the impermeable suberization of its superficial layers could be the result of a physiological response to that environment. Another work, dealing with embryogenic cultures of a $41 \mathrm{~B}$ clone $(V$. vinifera $\mathrm{cv}$. Chasselas $\times V$. berlandieri), showed that only $3 \%$ of the differentiated somatic embryos had a normal apical meristem between two well-defined cotyledons, the remaining 97\%, developed irregular cell structures in their apical area, that resulted in aberrant embryos without functional apices [40].

The effect of growth regulators on the DM was evaluated $30 \mathrm{~d}$ after calli transfer. For both cultivars, the addition of NAA to the DM, allowed normal embryo formation and development. However, the higher rates of embryo formation (21\% in Aragonez and $36 \%$ in Trincadeira), were obtained in culture 

Explants: Protocol Establishment and Histological Evaluation
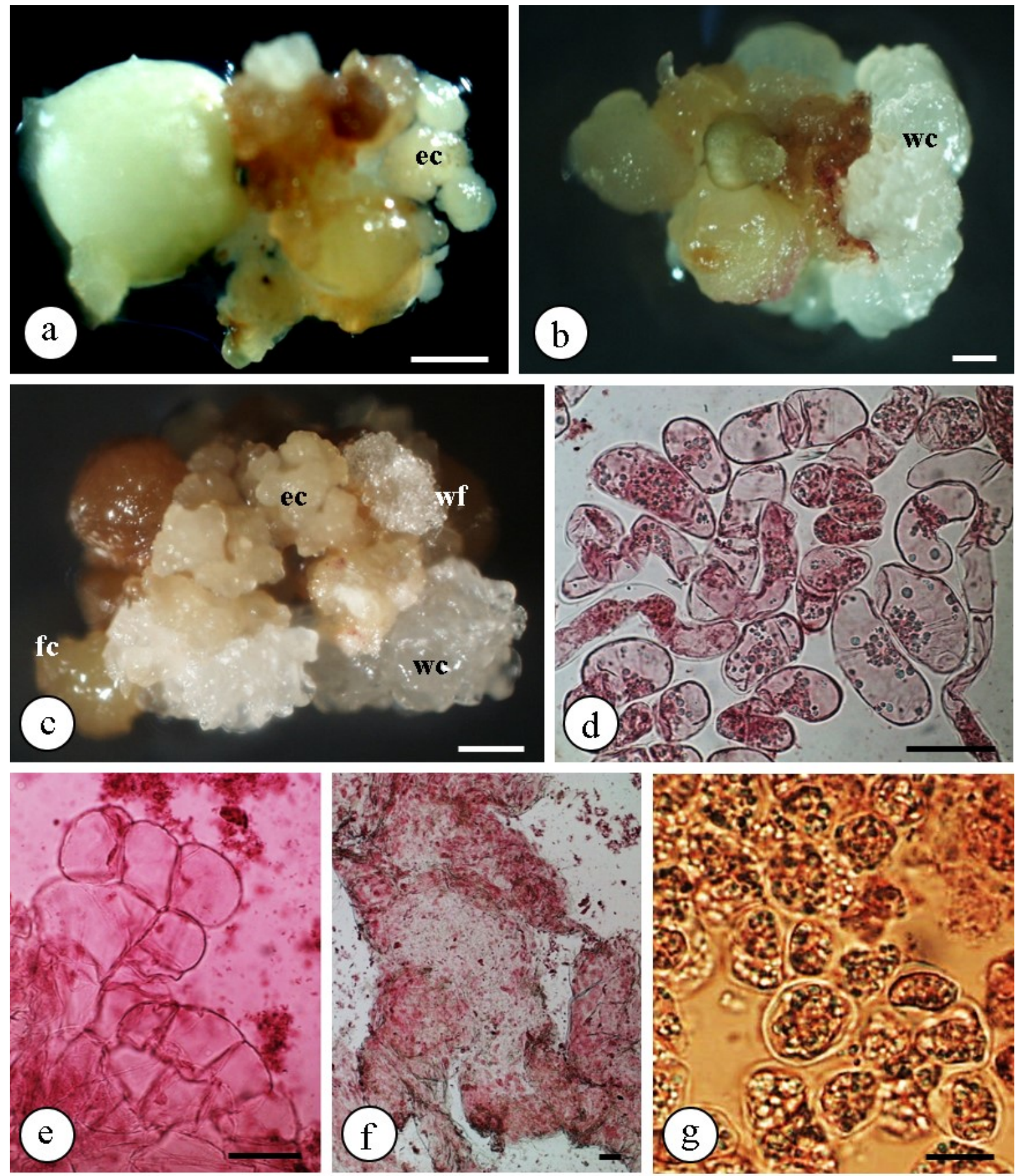

Fig. 4 Appearance of the carpel explants $28 \mathrm{~d}$ after inoculation in IM showing the different callus type developed (a, b, c); microscopic observations of the cells from each callus type (d, e, f, g) (d: from fc callus; e: from wf callus; f: from wc callus; g: from ec callus).

ec: callus with a white/light yellow color and a nodular appearance corresponding to the embryogenic callus; wf: white and filamentous callus; wc: white and compact callus; fc: brown and friable callus.

Bar in a, b and c: $1,000 \mu \mathrm{m}$; bar in d, e and f: $100 \mu \mathrm{m}$; bar in g: $25 \mu \mathrm{m}$. 

Explants: Protocol Establishment and Histological Evaluation
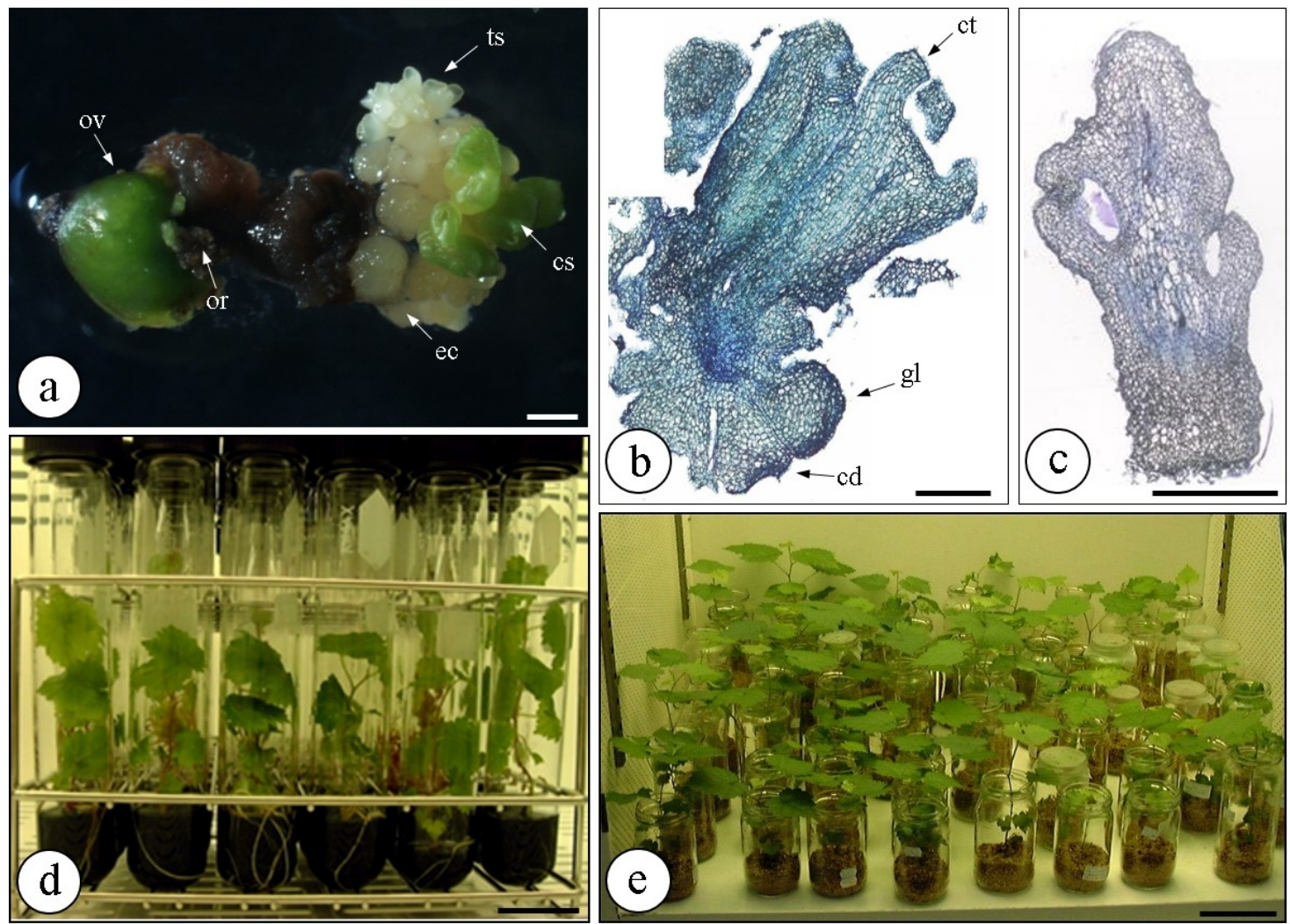

Fig. 5 Appearance of somatic embryos two weeks after transfer to DM and exposure at $16 \mathrm{~h}$ photoperiod, it is here visible the carpel with calli development only at the region of the receptacle tissue (a); histological examination showing embryos in different development stages belonging to the same cluster (b); histological examination showing an abnormal embryo with multiple deformed cotyledons (c); plants of cv. Trincadeira successfully converted in CM supplemented with activated charcoal (d); plants of cvs. Trincadeira and Aragonez during acclimatization to ex vitro conditions (e).

ov: ovary, or: ovary receptacle tissue, ec: embryogenic calli, cs: embryos in cotyledonary stage, ts: embryos in torpedo stage, cd: cordiforme stage, gl: globular stage, ct: cotyledonary stage.

Bar in a: $1 \mathrm{~cm}$; bar in b: $200 \mu \mathrm{m}$; bar in c: $500 \mu \mathrm{m}$; bar in d: $2 \mathrm{~cm}$; bar in e: $10 \mathrm{~cm}$.

media devoid of growth regulators (Table 3).

Media supplementation with growth regulators tends to have a strong impact in SE efficiency of grapevine cultured explants, being its presence specially required during the induction phase. For the second phase of SE, in which somatic embryo differentiation and development occurs, a culture media devoid of growth regulators is usually preferred [49-51]. The data here presented also revealed the lack of growth regulators on the DM media as the most appropriate condition to promote somatic embryo differentiation in both cultivars.

\subsection{Embryo Conversion}

The conversion of somatic embryos into plants is reported as an additional difficulty to establish efficient SE protocols. This is related with the difficulty in producing mature and well-developed somatic embryos able to grow into normal plants [39], or associated with the difficulty to break embryo dormancy in a similar way that occurs in natural dormancy of most seeds [52].

In the present study, the embryo developmental stage appeared as a crucial factor in conversion efficiency. For both cultivars, the total embryo conversion rates were higher when somatic embryos were individualized in the torpedo and early cotyledonary stages (group II) (Table 4). Embryos individualized on early developmental stages (group I), tend to turn brown, with no further visible development. 
Table 3 Effect of the growth regulators 2,4-D and NAA combined with BAP on somatic embryos differentiation.

\begin{tabular}{lllll}
\hline \multirow{2}{*}{$\mathrm{CM}$} & \multicolumn{2}{c}{ Aragonez } & \multicolumn{2}{c}{ Trincadeira } \\
\cline { 2 - 5 } & $\mathrm{N}(\mathrm{n})$ & Calli with embryos $(\%)$ & $\mathrm{N}(\mathrm{n})$ & Calli with embryos $(\%)$ \\
\hline Control & $48(8)$ & $21 \pm 0.23 \mathrm{a}$ & $102(17)$ & $36 \pm 0.31 \mathrm{a}$ \\
$1 \mu \mathrm{M}$ NAA: $0 \mu \mathrm{M}$ BAP & $72(12)$ & $15 \pm 0.18 \mathrm{a}$ & $72(12)$ & $28 \pm 0.28 \mathrm{a}$ \\
$5 \mu \mathrm{M}$ NAA: $1 \mu \mathrm{M}$ BAP & $72(12)$ & $6 \pm 0.11 \mathrm{ab}$ & $72(12)$ & $29 \pm 0.28 \mathrm{a}$ \\
$1 \mu \mathrm{M} 2,4-\mathrm{D}: 0 \mu \mathrm{M}$ BAP & $72(12)$ & $1 \pm 0.05 \mathrm{bc}$ & $72(12)$ & $1 \pm 0.05 \mathrm{~b}$ \\
$5 \mu \mathrm{M} 2,4-\mathrm{D}: 1 \mu \mathrm{M}$ BAP & $72(12)$ & $0 \pm 0.00 \mathrm{c}$ & $60(10)$ & $0 \pm 0.00 \mathrm{~b}$ \\
\hline
\end{tabular}

$\mathrm{N}$ : corresponds to the number of carpels transferred to CM; $n$ : corresponds to the number of Petri dishes analysed.

Different letters in the same column means significant differences $(p \leq 0.05)$ based on the Student-Newman-Keuls test Post-Hoc ANOVA.

Table 4 Effect of the initial embryo developmental stage on the embryo conversion.

\begin{tabular}{lllll}
\hline \multirow{2}{*}{ Embryo developmental stage } & \multicolumn{2}{c}{ Aragonez } & \multicolumn{2}{c}{ Trincadeira } \\
\cline { 2 - 5 } & $\mathrm{N}^{\mathrm{o}}$ ie & $\mathrm{ce}(\%)$ & $\mathrm{N}^{\mathrm{o}}$ ie & $\mathrm{ce}(\%)$ \\
\hline Group I: globular, cordiforme and beginning of torpedo & 100 & $0 \pm 1.12 \mathrm{c}$ & 100 & $0 \pm 1.07 \mathrm{c}$ \\
Group II: torpedo and beginning of cotyledonary & 100 & $13 \pm 1.12 \mathrm{a}$ & 100 & $21 \pm 1.07 \mathrm{a}$ \\
Group III: cotyledonary & 100 & $7 \pm 1.12 \mathrm{~b}$ & 100 & $9 \pm 1.07 \mathrm{~b}$ \\
\hline
\end{tabular}

$\mathrm{N}^{\mathrm{o}}$ ie: number of inoculated embryos in Petri dishes containing CM; ce: converted embryos.

Different letters in the same column means significant differences $(p \leq 0.05)$ based on the Student-Newman-Keuls test Post-Hoc ANOVA.

In the same way, late individualization of somatic embryos (group III), were usually associated with abnormal development and consequent low conversion rates. Emershad and Ramming [53], already reported the embryo size as a critical factor on the potentiality of the embryos to convert into normal plants. Accordingly, smaller embryos (1-1.99 $\mathrm{mm})$, as well as the bigger ones (5-7.99 $\mathrm{mm})$, present low conversion potentiality.

Despite previous reports showing that cold treatment as well as gibberellic acid, can successfully be used to overcome embryo dormancy in grape somatic embryos [43, 52, 54], in the present research, the positive effect of those factors, highly depended on the genotype.

The effectiveness of media supplementation with 1 $\mu \mathrm{M} \quad \mathrm{GA}_{3}$ revealed to differently affect the two genotypes under evaluation, being the conversion rates significantly higher than the control in Trincadeira, 52\% compared with $49 \%$ and lower in Aragonez, with only $1 \%$ of conversion rate, in comparison with the $11 \%$ achieved in the control (Table 5). For both cultivars, the presence of $\mathrm{GA}_{3}$ was associated with the development of malformed cotyledons.

The use of a cold treatment after embryo individualization and inoculation in CM, also revealed a marked effect on the number of recovered embryos. The incubation at $4{ }^{\circ} \mathrm{C}$ for $5 \mathrm{~d}$ showed the highest embryos conversion rate for both cultivars, with approximately two-fold increase of embryos conversion percentage in Aragonez over the control. Larger periods of incubation were associated in both cultivars with a decrease on the embryo's conversion efficiency.

It can be said that both $\mathrm{GA}_{3}$ and cold treatments can increase the embryo conversion rates, but their effects are highly depending on the genotype. This result indicates that both factors affect the same biological process as earlier proposed by several authors [43, 49, 52, 55-57].

Although low somatic embryos conversion rates have been associated with abnormal morphology and dormancy, that have led to the manipulation of factors to directly overcome dormancy (use of gibberellins and cold treatments), some other factors have also been considered to promote embryo conversion. The 
exogenous supplement of CM media with cytokines is one of those factors.

It is well known that cytokinin plays key roles in the regulation of root and shoot development and have been demonstrated that its exogenous application induces an enlargement of the shoot meristem (see review in Ref. [58]). Previous works developed in $V$. longii and $V$. rotundifolia showed that the addition of $1 \mu \mathrm{M}$ BAP to the culture medium promoted shoot elongation $[6,59]$. Nevertheless, in the present trials, BAP $(0.4 \mu \mathrm{M})$ didn't show, in both cultivars, a significant increase of embryos conversion rate, and, in both cases, it was associated with the development of friable white calli in the hypocotyl region. The differential behavior upon application of IBA in the culture medium could not only be associated with the different concentrations of BAP used but also be associated with a genotype effect.

The genotype dependence previously associated with embryos conversion efficiency in $V$. vinifera $[7$, 19], also seen here as affecting the capacity of Trincadeira and Aragonez embryos conversion in all treatments tested (chilling and media supplementation with activated charcoal, BAP or $\mathrm{GA}_{3}$ ) lead to the identification of different optimal conditions for somatic embryos conversion.

Cold treatment with embryo incubation during $5 \mathrm{~d}$ at $4{ }^{\circ} \mathrm{C}$ presented the highest embryo conversion rates in Aragonez, with $24 \%$ of the total inoculated embryos converted to normal plantlets (Table 5). However, culture medium supplementation with activated charcoal revealed to be the most appropriate for Trincadeira embryo conversion with $57 \%$ of conversion rate (Table 5, Fig. 5d).

Activated charcoal has been used by some researchers in culture medium associated with the different steps of a SE protocol, that includes the embryogenic calli induction [11], embryos differentiation $[11,28,60]$ and conversion of somatic embryos to plantlets [23, 43, 61]. Nevertheless, only one study [43] carried on grapevine, reported a positive effect of activated charcoal on somatic embryos conversion.

Several reasons have been pointed out to explain the positive effect of activated charcoal associated to the SE. Hébert-Soulé et al. [60], mentioned that the role of activated charcoal is related with the absorption of potential germination inhibitors and remaining hormones, allowing the germination of torpedo-embryos and their conversion into plantlets.

Table 5 Effect of different treatments on embryos conversion.

\begin{tabular}{llrll}
\hline \multirow{2}{*}{ Treatments } & \multicolumn{2}{c}{ Aragonez } & Trincadeira \\
\cline { 2 - 5 } & ie & ce $(\%)^{*}$ & ie & ce $(\%)^{*}$ \\
\hline Medium supplements & 100 & $11 \pm 1.32 \mathrm{~b}$ & 100 & $49 \pm 1.62 \mathrm{~d}$ \\
\hline Control $(*)$ & 100 & $14 \pm 1.32 \mathrm{a}$ & 100 & $57 \pm 1.62 \mathrm{a}$ \\
Activated charcoal $(2 \mathrm{mg} / \mathrm{L})$ & $7 \pm 1.32 \mathrm{c}$ & 100 & $54 \pm 1.62 \mathrm{~b}$ \\
$\mathrm{BAP}(0.4 \mu \mathrm{M})$ & 100 & $1 \pm 1.32 \mathrm{~d}$ & 100 & $52 \pm 1.62 \mathrm{c}$ \\
$\mathrm{GA}_{3}(1 \mu \mathrm{M})$ & 100 & & & $49 \pm 1.32 \mathrm{a}$ \\
\hline Incubation at $4^{\circ} \mathrm{C}$ & & $11 \pm 1.32 \mathrm{c}$ & 100 & $49 \pm 1.32 \mathrm{a}$ \\
\hline Control $(0 \mathrm{~d})$ & 100 & $24 \pm 1.32 \mathrm{a}$ & 100 & $35 \pm 1.32 \mathrm{~b}$ \\
$5 \mathrm{~d}$ & 100 & $22 \pm 1.32 \mathrm{~b}$ & 100 & $28 \pm 1.32 \mathrm{c}$ \\
$15 \mathrm{~d}$ & 100 & $8 \pm 1.32 \mathrm{~d}$ & 100 & $\mathrm{CA}$ \\
$25 \mathrm{~d}$ & 100 & & & \\
\hline
\end{tabular}

*The control for medium supplement treatments correspond to a medium devoid activated charcoal, BAP and GA 3 ; ie: number of inoculated embryos in tubes containing CM; ce: converted embryos.

Different letters in the same column means significant differences $(p \leq 0.05)$ based on the Student-Newman-Keuls test Post-Hoc ANOVA. 
From the total of successfully converted embryos, $82 \%$ of the in vitro Trincadeira plantlets and $33 \%$ of the Aragonez were acclimatized to the ex vitro conditions (Fig. 5e).

\section{Conclusions}

Despite the better results globally achieved with the cultivar Aragonez, it can be assumed that, in general, the most reliable conditions for SE induction and differentiation phases are the same for the two cultivars under evaluation. The absence of cold pre-treatments on the inflorescences and culture incubation temperature of $28{ }^{\circ} \mathrm{C}$ were the conditions selected for SE induction. The use of $\mathrm{CM}$, lacking on growth regulators, revealed to be the most appropriate condition for the embryo differentiation phase in both cultivars. Concerning its conversion, somatic embryos showed high genotype dependence with the inoculation during $5 \mathrm{~d}$ at $4{ }^{\circ} \mathrm{C}$ being suitable for Aragonez, while the presence of activated charcoal in the $\mathrm{CM}$ revealed to be the most appropriate methodology for embryo conversion in Trincadeira. The histological observations allowed to identify the tissues involved on the SE process and revealed that the embryogenic calli preferentially appear from the receptacle parenchyma cells, while no cell division was observed in the embryo sac. It was possible to conclude that only the calli with nodular appearance, presenting cells with dense cytoplasm, visible starch grains and prominent nuclei and nucleoli, were able to differentiate into embryonic structures. Asynchronous embryos differentiation and formation of abnormal embryos were visible in both cultivars.

\section{Acknowledgments}

This work was funded by National Funds through FCT-Foundation for Science and Technology under the Projects PEst-C/AGR/UI0115/2011 and UID/AGR/00115/2013. HGC was also financed by
FCT though the grant SFRH/BD/3060/2000. The authors also wish to show their thanks to Mr. Jorge Böhm from Plansel S.A. for the plant material and to Virginia Sobral for helping with the in vitro cultures.

\section{References}

[1] International Organization of Vine and Wine (OIV). 2017. World Viticulture Situation-Statistical Report on World Viticulture. OIV.

[2] Figueiredo, A., Cardoso, H., and Pais, M. S. 2007. "Contribution of Biotechnology for Grapevine Breeding in Portugal." In The Great Book of Grapevine-Part 2, edited by Böhm, H. J. Chaves Ferreira Publicações S.A, Portugal, 63-4. (in Portuguese)

[3] Gray, D. J., Li, Z. T., and Dhekney, S. A. 2014. "Precision Breeding of Grapevine (Vitis vinifera L.) for Improved Traits." Plant Sci. 228: 3-10.

[4] Cardoso, H. G., Peixe, A., Baldé, A., and Pais, M. S. 2004. "Optimization of a Particle Bombardment Protocol for $V$. vinifera cv. Trincadeira and cv. Aragonez Transformation." Acta Hortic. 652: 407-13.

[5] Cardoso, H. G., Figueiredo, A., Baldé, A., Pais, M. S., and Peixe, A. A. 2012. "Genetic Transformation of $V$. vinifera-Two Alternative Systems under Evaluation." Acta Hortic. 931: 421-7.

[6] Gray, D. J., and Mortensen, J. A. 1987. "Initiation and Maintenance of Long Term Somatic Embryogenesis from Anthers and Ovaries of Vitis longii Microsperma." Plant Cell Tissue Organ Cult. 9: 73-80.

[7] Stamp, J. A., and Meredith, C. P. 1988. "Proliferative Somatic Embryogenesis from Zygotic Embryos of Grapevine.” J. Amer. Soc. Hort. Sci. 113: 941-5.

[8] Matsuta, N., and Hirabayashi, T. 1989. "Embryogenic Cell Lines from Somatic Embryos of Grape (Vitis vinifera L.)." Plant Cell Rep. 7: 684-7.

[9] Gray, D. J. 1992. "Somatic Embryogenesis and Plant Regeneration from Immature Zygotic Embryos of Muscadine Grape (Vitis rotundifolia) Cultivars." Am. J. Bot. 79 (5): 542-6.

[10] Martinelli, L., Bragagna, P., Poletti, V., and Scienza, A. 1993. "Somatic Embryogenesis from Leaf- and Petiole-Derived Callus of Vitis rupestris." Plant Cell Rep. 12: 207-10.

[11] Perl, A., Saad, S., Sahar, N., and Holland, D. 1995. "Establishment of Long-Term Embryogenic Cultures of Seedless Vitis vinifera Cultivars-A Synergistic Effect of Auxins and the Role of Abscisic Acid." Plant Sci. 104: 193-200.

[12] Krul, W. R., and Worley, J. F. 1977. "Formation of Adventitious Embryos in Callus Cultures of 'Seyval', a 
French Hybrid Grape." J. Amer. Soc. Hort. Sci. 102: 360-3.

[13] Bouquet, A., Piganeau, B., and Lamaison, A. M. 1982. "Genotype Effect on Calli, Embryos and Full Plants Production, after in Vitro Culture of Vitis Anthers." $C R$ Acad. Sci. Paris 295: 569-74. (in French)

[14] Rajasekaran, K., and Mullins, M. G. 1983. "Influence of Genotype and Sex-Expression on Formation of Plantlets by Cultured Anthers of Grapevines." Agronomie 3: 233-8.

[15] Mozsár, J., and Viczián, O. 1996. "Genotype Effect on Somatic Embryogenesis and Plant Regeneration of Vitis spp." Vitis 35: 155-7.

[16] San Pedro, T., Gammoudi, N., Peiró, R., Olmos, A., and Gisbert, C. 2017. "Somatic Embryogenesis from Seeds in a Broad Range of Vitis vinifera L. Varieties: Rescue of True-to-Type Virus-Free Plants.” BMC Plant Biol. 17: 226.

[17] Cardoso, H. G., Campos, M. C., Pais, M. S., and Peixe, A. 2010. "Use of Morphometric Parameters for Tracking Ovule and Microspore Evolution in Grapevine (Vitis vinifera L., cv. Aragonez) and Evaluation of Their Potential to Improve in Vitro Somatic Embryogenesis Efficiency from Gametophyte Tissues." In Vitro Cell. Dev. Biol.-Plant. 46: 499-508.

[18] Dhekney, S. A., Li, Z. T., and Gray, D. J. 2011. "Factors Influencing Induction and Maintenance of Vitis rotundifolia Michx. Embryogenic Cultures.” Plant Cell Tissue Organ Cult. 105: 175-80.

[19] Dhekney, S. A., Li, Z. T., Compton, M. E., and Gray, D. J. 2009. "Optimizing Initiation and Maintenance of Vitis Embryogenic Cultures.” HortScience 44: 1400-6.

[20] Alavijeh, M. K., Ebadi, A., Zarei, A., and Omidi, M. 2016. "Somatic Embryogenesis from Anther, Whole Flower and Leaf Explants of Some Grapevine Cultivars." Plant Tissue Cult. Biotechnol. 26: 219-30.

[21] Cutanda, M. C., Bouquet, A., Chatelet, P., Lopez, G., Botella, O., Montero, F. J., and Torregrosa, L. 2008. "Somatic Embryogenesis and Plant Regeneration of Vitis vinifera Cultivars Macabeo and Tempranillo." Vitis-J. Grapevine Res. 47: 159-62.

[22] González-Benito, M. E., Martín, C., and Vidal, J. R. 2009. "Cryopreservation of Embryogenic Cell Suspensions of the Spanish Grapevine Cultivars Albariño and Tempranillo." Vitis-J. Grapevine Res. 48: 131-6.

[23] Vidal, J. R., Rama, J., Taboada, L., Martin, C., Ibañez, M., Segura, A., and González-Benito, M. E. 2009. "Improved Somatic Embryogenesis of Grapevine (Vitis vinifera) with Focus on Induction Parameters and Efficient Plant Regeneration." Plant Cell Tissue Organ Cult. 96: 85-94.

[24] Prado, M. J., Rodriguez, E., Rey, L., González, M. V., Santos, C., and Rey, M. 2010. "Detection of Somaclonal
Variants in Somatic Embryogenesis-Regenerated Plants of Vitis vinifera by Flow Cytometry and Microsatellite Markers." Plant Cell Tissue Organ Cult. 103: 49-59.

[25] Prado, M. J., Grueiro, M. P., González, M. V., Testillano, P. S., Domínguez, C., López, M., and Rey, M. 2010. "Efficient Plant Regeneration through Somatic Embryogenesis from Anthers and Ovaries of Six Autochthonous Grapevine Cultivars from Galicia (Spain)." Sci. Hortic. 125: 342-52.

[26] Gambino, G., Navarro, B., Vallania, R., Gribaudo, I., and Di Serio, F. 2011. "Somatic Embryogenesis Efficiently Eliminates Viroid Infections from Grapevines." Eur. J. Plant Pathol. 130: 511-9.

[27] Gambino, G., Minuto, M., Boccacci, P., Perrone, I., Vallania, R., and Gribaudo, I. 2011. "Characterization of Expression Dynamics of WOX Homeodomain Transcription Factors during Somatic Embryogenesis in Vitis vinifera." J. Exp. Bot. 62: 1089-101.

[28] Acanda, Y., Prado, M. J., González, M. V., and Rey, M. 2013. "Somatic Embryogenesis from Stamen Filaments in Grapevine (Vitis vinifera L. cv. Mencía): Changes in Ploidy Level and Nuclear DNA Content." In Vitro Cell. Dev. Biol.-Plant 49 (3): 276-84.

[29] Li, Z. T., Kim, K. H., Dhekney, S. A., Jasinski, J. R., Creech, M. R., and Gray, D. J. 2014. "An Optimized Procedure for Plant Recovery from Somatic Embryos Significantly Facilitates the Genetic Improvement of Vitis." Hortic. Res. 1. Article number: 14027. https://doi.org/10.1038/hortres.2014.27.

[30] Dhekney, S. A., Li, Z. T., Grant, T. N. L., and Gray, D. J. 2016. "Somatic Embryogenesis and Genetic Modification of Vitis." In In Vitro Embryogenesis in Higher Plants, edited by Germanà, M. A., and Lambardi, M. Springer Science + Business Media New York, 263-77.

[31] Mauro, C. L., Nef, C., and Fallot, J. 1986. "Stimulation of Somatic Embryogenesis and Plant Regeneration from Anther Culture of Vitis vinifera cv. Cabernet-Sauvignon." Plant Cell Rep. 5: 377-80.

[32] Nakano, M., Watanabe, Y., and Hoshino, Y. 2000. "Histological Examination of Callogenesis and Adventitious Embryogenesis in Immature Ovary Culture of Grapevine (Vitis vinifera L.)." J. Hortic. Sci. Biotechnol. 75: 154-60.

[33] Gribaudo, I., Gambino, G., and Vallania, R. 2004. "Somatic Embryogenesis from Grapevine Anthers: The Optimal Developmental Stage for Collecting Explants." Am. J. Enol. Vitic. 55: 427-30.

[34] Perrin, M., Gertz, C., and Masson, J. E. 2004. "High Efficiency Initiation of Regenerable Embryogenic Callus from Anther Filaments of 19-Grapevine Genotypes Grown Worldwide." Plant Sci. 167: 1343-9.

[35] Kikkert, J. R., Striem, M. J., Vidal, J. R., Wallace, P. G., 

Explants: Protocol Establishment and Histological Evaluation

Barnard, J., and Reisch, B. I. 2005. "Long-Term Study of Somatic Embryogenesis from Anthers and Ovaries of 12 Grapevine (Vitis sp.) Genotypes." In Vitro Cell. Dev. Biol.-Plant 41 (3): 232-9.

[36] Gambino, G., Ruffa, P., Vallania, R., and Gribaudo, I. 2007. "Somatic Embryogenesis from Whole Flowers, Anthers and Ovaries of Grapevine (Vitis spp.)." Plant Cell Tissue Organ Cult. 90: 79-83.

[37] Cardoso, H. G., Peixe, A. V., and Pais, M. S. 2009. "In Vitro Somatic Embryogenesis from Stamens of Trincadeira, a Portuguese Vitis vinifera L. Cultivar." Acta Hortic. 812: 305-11.

[38] Coutos-Thevenot, P., Goebel-Tourand, I., Mauro, M. C., Jouanneau, J. P., Boulay, M., Deloire, A., and Guern, J. 1992. "Somatic Embryogenesis from Grapevine Cells. I-Improvement of Embryo Development by Changes in Culture Conditions." Plant Cell Tissue Organ Cult. 29 (2): 125-33.

[39] Perrin, M., Martin, D., Joly, D., Demangeat, G., This, P., and Masson, J. E. 2001. "Medium-Dependent Response of Grapevine Somatic Embryogenic Cells." Plant Sci. 161: 107-16.

[40] Goebel-Tourand, I., Mauro, M. C., Sossountzov, L., Miginiac, E., and Deloire, A. 1993. "Arrest of Somatic Embryo Development in Grapevine: Histological Characterization and the Effect of ABA, BAP and Zeatin in Stimulating Plantlet Development." Plant Cell Tissue Organ Cult. 33: 91-103.

[41] Peixe, A., Barroso, J., Potes, A., and Pais, M. S. 2004. "Induction of Haploid Morphogenic Calluses from in Vitro Cultured Anthers of Prunus armeniaca cv. 'Harcot'." Plant Cell Tissue Organ Cult. 77 (1): 35-41.

[42] Motoike, S. Y., Skirvin, R. M., Norton, M. A., and Otterbacher, A. G. 2001. "Somatic Embryogenesis and Long Term Maintenance of Embryogenic Lines from Fox Grapes." Plant Cell Tissue Organ Cult. 66: 121-31.

[43] López-Pérez, A. J., Carreño, J., Martínez-Cutillas, A., and Dabauza, M. 2005. "High Embryogenic Ability and Plant Regeneration of Table Grapevine Cultivars (Vitis vinifera L.) Induced by Activated Charcoal." Vitis 44 (2): 79-85.

[44] Nakano, M., Sakakibara, T., Watanabe, Y., and Mii, M. 1997. "Establishment of Embryogenic Cultures in Several Cultivars of Vitis vinifera and $V . \times$ labruscana." Vitis 36 : 141-5.

[45] Torregrosa, L., Torres-Vials, M., and Bouquet, A. 1995. "Somatic Embryogenesis from Leaves of Vitis $\times$ Muscadinia Hybrids." Vitis 24: 239-40.

[46] Mullins, M. G., and Srinivasan, C. 1976. "Somatic Embryos and Plantlets from an Ancient Clone of the Grapevine (cv. Cabernet-Sauvignon) by Apomixis in Vitro." J. Exp. Bot. 27: 1022-30.

[47] Srinivasan, C., and Mullins, M. G. 1980.
"High-Frequency Somatic Embryo Production from Unfertilized Ovules of Grapes." Sci. Hortic. 13: 245-52.

[48] Faure, O. 1990. "Vitis rupestris and Zygotic Embryos of Vitis sp.: Morphology, Histology, Histochemical and Development." Can. J. Bot. 68 (11): 2305-15.

[49] Faure, O., Aarrouf, J., and Nougarède, A. 1996. "Ontogenesis, Differentiation and Precocious Germination in Anther-Derived Somatic Embryos of Grapevine (Vitis vinifera L.): Embryonic Organogenesis." Ann. Bot. 78: 29-37.

[50] Faure, O., Aarrouf, J., and Nougarède, A. 1996. "Ontogenesis, Differentiation and Precocious Germination in Anther-Derived Somatic Embryos of Grapevine (Vitis vinifera L.): Proembryogenesis." Ann. Bot. 78: 23-8.

[51] Vidal, J. R., Kikkert, J. R., Wallace, P. G., and Reisch, B. I. 2003. "High-Efficiency Biolistic Co-transformation and Regeneration of Chardonnay (Vitis vinifera L.) Containing npt-II and Antimicrobial Peptide Genes." Plant Cell Rep. 22: 252-60.

[52] Larrouy, J., Jaksons, P., and Bicknell, R. 2017. "Response Interactions in Grape Somatic Embryogenic Cultures to Cold and Gibberellic Acid Treatments to Overcome Embryo Dormancy." Plant Cell Tissue Organ Cult. 129: 45-52.

[53] Emershad, R. L., and Ramming, D. W. 1994. "Somatic Embryogenesis and Plant Development from Immature Zygotic Embryos of Seedless Grapes (Vitis vinifera L.)." Plant Cell Rep. 16: 6-12.

[54] Rajasekaran, K., and Mullins, M. G. 1979. "Embryos and Plantlets from Cultured Anthers of Hybrid Grapevines." J. Exp. Bot. 30: 399-407.

[55] Rajasekaran, K., Vine, J., and Mullins, M. G. 1982. "Dormancy in Somatic Embryos and Seeds of Vitis: Changes in Endogenous Abscisic Acid during Embryogeny and Germination.” Planta 154: 139-44.

[56] Takeno, K., Koshioka, M., Pharis, R. P., Rajasekaran, K., and Mullins, M. G. 1983. "Endogenous Gibberellin-Like Substances in Somatic Embryos of Grape (Vitis vinifera $\times$ Vitis rupestris) in Relation to Embryogenesis and the Chilling Requirement for Subsequent Development of Mature Embryos." Plant Physiol. 73: 803-8.

[57] Gray, D. J. 1989. "Effects of Dehydration and Exogenous Growth Regulators on Dormancy, Quiescence and Germination of Grape Somatic Embryos." Vitro Cell. Dev. Biol. 25: 1173-8.

[58] Del Bianco, M., Giustini, L., and Sabatini, S. 2013. "Spatiotemporal Changes in the Role of Cytokinin during Root Development." New Phytologist 199: 324-38.

[59] Robacker, C. 1993. "Somatic Embryogenesis and Plant Regeneration from Muscadine Grape Leaf Explants." HortScience 28 (1): 53-5. 

Explants: Protocol Establishment and Histological Evaluation

[60] Martinelli, L., Gribaudo, I., Bertoldi, D., Candioli, E., and Poletti, V. 2001. "High Efficiency Somatic Embryogenesis and Plant Germination in Grapevine Cultivars Chardonnay and Brachetto a Grappolo Lungo.”
Vitis 40 (3): 111-5.

[61] Hébert-Soulé, D., Kikkert, J. R., and Reisch, B. I. 1995. "Phosphinothricin Stimulates Somatic Embryogenesis in Grape (Vitis sp. L.).” Plant Cell Rep. 14: 380-4. 